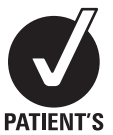

CHOICE

\title{
Patient perception of dyskinesia in Parkinson's disease
}

\author{
S W Hung, ${ }^{1,2}$ G M Adeli, ${ }^{1}$ T Arenovich, ${ }^{3}$ S H Fox, ${ }^{1}$ A E Lang ${ }^{1}$
}

\begin{abstract}
- Additional appendices are published online only. To view these files please visit the journal online (http://jnnp.bmj.com).

${ }^{1}$ Movement Disorders Centre, Toronto Western Hospital and the Division of Neurology, University of Toronto, Toronto, Canada

${ }^{2}$ Department of Neurology, Medical College of Wisconsin, Milwaukee, Wisconsin, USA ${ }^{3}$ Clinical Research Department, Centre of Addiction and Mental Health, Toronto, Canada
\end{abstract}

\section{Correspondence to} Dr Anthony E Lang, Movement Disorders Centre, University of Toronto, 399 Bathurst Street, 7 Mc-L, Toronto, Ontario M5T 2S8, Canada:

lang@uhnresearch.ca

Received 21 January 2009 Revised 22 June 2009

Accepted 24 June 2009 Published Online First 28 July 2010
ABSTRACT

Objective To evaluate the perception of patients with Parkinson's disease (PD) regarding dyskinesia.

Design Multicentre survey.

Setting Tertiary referral centres.

Patients Patients with PD participated in a survey: those not on dopaminergic medications (group I), those on dopaminergic medications without dyskinesia (group II) and those on dopaminergic medications with dyskinesia (group III).

Intervention After a short standardised description and explanation of dyskinesia was provided, patients were asked about the nature and source of prior knowledge of dyskinesia. They were then asked about their perceptions of dyskinesia. Patients in group III were also asked about the duration, the severity of dyskinesia and whether their perception of this problem had changed since its appearance.

Main outcome measures Level of concern regarding dyskinesia and whether their perception of dyskinesia would have changed their preference of treatment. Results 259 PD patients completed the survey (group I, 52; group II, 102; group III, 105). Patients with dyskinesia were significantly less concerned about dyskinesia than patients without dyskinesia and were more likely to choose dyskinesia over being parkinsonian. Patients who required fewer changes in medications because of dyskinesia were more likely to choose dyskinesia over parkinsonism.

Conclusion Patients with PD experiencing dyskinesia are less likely to be concerned about dyskinesia and more likely to prefer dyskinesia over parkinsonian symptoms than patients without dyskinesia.

Concern about the development of dopaminergic drug-induced dyskinesia has greatly influenced clinical research studies and management decisions in Parkinson's disease (PD) for more than two decades. Several studies have shown that initial therapy with a dopamine agonist, rather than L-dopa, results in a significantly lower incidence of dyskinesia. ${ }^{1}{ }^{2}$ However, dopamine agonists may not provide an equivalent symptomatic response to that obtained from L-dopa, and certain side effects such as sedation and excessive daytime somnolence, leg oedema, hallucinations and impulse control disorders are all more common with agonists than levodopa. ${ }^{3-9}$

\section{OBJECTIVES}

To evaluate patients' opinions and attitudes towards dyskinesia and whether and how they would like treatment decisions to be influenced by these concerns ("perception" of dyskinesia).

\section{METHODS}

English-speaking patients with $\mathrm{PD}^{10}$ were recruited between September 2003 and March 2006 from both the Movement Disorders Centre at the University of Toronto and the Neurology Clinic at the Medical College of Wisconsin.

Exclusion criteria included the presence of any other neurological disorder, intellectual impairment, significant depression and failure to distinguish the difference between dyskinesia and parkinsonian symptoms due to motor fluctuation despite explanation by the interviewer.

Surveys, Unified Parkinson's Disease Rating Scale (UPDRS) scores and, where appropriate, the Lang-Fahn Activities of Daily Living Dyskinesia Scale $^{11}$ were administered by movement disorders neurologists trained to conduct them in a standardised fashion.

The patients were first read a standard short passage with information about the cause and nature of dyskinesia (see online appendices for standard passage and surveys administered). Patients were divided into three groups: (1) patients not taking any dopaminergic medication, (2) patients on dopaminergic medication(s) but without dyskinesia and (3) patients on dopaminergic medication(s) with dyskinesia. Each group of patients was asked slightly different questions, but all were asked whether or not they had any prior knowledge of dyskinesia and its cause, how they perceived the importance of dyskinesia, and whether they would prefer dyskinesia or parkinsonian symptoms if they had to choose. Perception of dyskinesia was rated as 0 ("not concerned at all") to 3 ("extremely concerned"). For group III, patients were also asked how many times their treatment had to be changed because of dyskinesia and whether they wished their initial treatment strategy had been different given what they knew currently. This information was checked against patients' medical records at the two study sites to verify its accuracy when available.

\section{STATISTICAL ANALYSIS}

Group differences were evaluated. A series of analyses or variance followed by Bonferroni-adjusted pairwise comparisons were used to evaluate differences in current age, age of onset, age at diagnosis, follow-up duration, duration to treatment and UPDRS scores. Within each group, to evaluate whether prior awareness of dyskinesia was associated with patient concern about dyskinesia, a series of $\chi^{2}$ /Fisher's exact tests were performed. Among those with prior knowledge of dyskinesia, an additional series of Fisher's exact tests and a Kruskal-Wallis test were performed to assess 
whether the means by which they acquired knowledge of dyskinesia affected their degree of concern about dyskinesia.

In group III, a series of $\chi^{2}$ tests, Fisher's exact tests and Mann-Whitney U tests were performed to study whether the number of previous changes to the patient's medications because of dyskinesia changed their perception of dyskinesia. Bonferroniadjusted pairwise comparisons were used to compare the Lang-Fahn Activities of Daily Living Dyskinesia Scale score and the level of concern.

To compare the degree of concern about dyskinesia among the groups, a series of $\chi^{2}$ /Fisher's exact (categorical), Kruskal-Wallis (quantitative) tests and Bonferoni-adjusted pairwise comparisons were performed.

A p value of $<0.05$ was considered significant.

\section{RESULTS}

A total of 259 patients were enrolled. Table 1 lists all patient characteristics including the main sources of information on dyskinesia.

\section{All groups}

The degree of concern with regard to dyskinesia (0-3) differed significantly across the three groups: groups I and II were highest (mean $1.63(0.79)$ and $1.22(0.86)$ ), and group III was the lowest (mean $0.86(0.75)$ ). Groups I and II (without dyskinesia) did not differ significantly from one another (adjusted $\mathrm{p}=0.13$ ); both demonstrated significantly greater concern than group III (existing dyskinesia) (adjusted $\mathrm{p}<0.01$ ). In groups I and II, slightly more than half indicated that they would rather tolerate worsened parkinsonian symptoms (group I 53\%, group II 51\%) than have dyskinesia, whereas in group III, $83 \%$ chose to tolerate dyskinesia (adjusted $\mathrm{p}<0.01$ for comparisons between groups I and III and groups II and III). The difference between groups I and II was not significant (figure 1).

\section{Group III (with dyskinesia)}

The severity of the Lang-Fahn Activities of Daily Living Dyskinesia Scale score correlated with concern about their current level of dyskinesia $(\mathrm{r}=0.56, \mathrm{p}<0.0001)$, but it did not have any significant influence on their concern regarding treatment choices at the time of commencement of treatment $(\mathrm{r}=0.10, \mathrm{p}=0.3)$. Overall, most patients preferred to tolerate dyskinesia (83\%) rather than worsening of their parkinsonian symptoms $(17 \%)$. This result was still evident but less pronounced among those who had required changes to their medications because of dyskinesia; these patients expressed significantly higher concern about dyskinesia than those who had not required any changes to their medication regimen $(p<0.01)$ (figure 1$)$. The number of medication changes did not influence the degree of concern.

In patients who knew about dyskinesia before their onset, when asked how the severity of dyskinesia compared with what they expected before experiencing them, $28 \%$ reported that their dyskinesia were on par with their expectations, $47 \%$ thought their dyskinesia were not as bad as they had expected and $25 \%$ felt they were worse than expected.

\section{DISCUSSION}

The results of this survey confirm what many movement disorders neurologists have observed in their clinical practice but has never been proven by a systematic study, that most patients

Table 1 Patient characteristics and comparison of prior knowledge of dyskinesia*

\begin{tabular}{|c|c|c|c|}
\hline & Group I (untreated) & $\begin{array}{l}\text { Group II (treated; } \\
\text { without dyskinesia) }\end{array}$ & $\begin{array}{l}\text { Group III (treated; } \\
\text { with dyskinesia) }\end{array}$ \\
\hline Number of patients & 52 & 102 & 105 \\
\hline Number of males (\%) & $33(63.5)$ & $53(52.0)$ & $71(67.6) \dagger$ \\
\hline Current age (years) (SD) & $62.4(12.6)$ & $65.4(10.6)$ & $64.1(9.3) \dagger$ \\
\hline Age at diagnosis (mean (SD)) & $60.4(12.8)$ & $60.5(11.6)$ & $53.8(9.7) \neq$ \\
\hline $\begin{array}{l}\text { Time followed in clinic (months) } \\
\text { (median (min, max)) }\end{array}$ & $5.0(0,112)$ & $30.5(0,155)$ & $70.0(0,233) \S$ \\
\hline $\begin{array}{l}\text { Time from diagnosis to starting } \\
\text { dopaminergic agent (months) } \\
\text { (median, min, max) }\end{array}$ & Not applicable & $2.0(0,120)$ & $0.0(0,12) \Phi$ \\
\hline UPDRS III score mean (SD) & $19.7(9.7)$ & $21.9(9.5)$ & $24.8(12.1)^{* *}$ \\
\hline UPDRS 032 mean (SD) & 0 & 0 & $1.5(0.96)$ \\
\hline UPDRS 033 mean (SD) & 0 & 0 & $1.0(0.92)$ \\
\hline $\begin{array}{l}\text { Lang-Fahn Dyskinesia Scale score } \\
\text { (maximum score }=20 \text { ) (mean (SD)) }\end{array}$ & 0 & 0 & $5.6(4.9)$ \\
\hline $\begin{array}{l}\text { Source of information about dyskinesia if } \\
\text { patient was aware of dyskinesia before } \\
\text { survey (or, in group III, before developing } \\
\text { dyskinesia) }\end{array}$ & $\begin{array}{l}\text { Medical sources } n=7(30 \%) \text {, } \\
\text { media } n=8(34 \%) \text {, other } \\
\text { patients } n=3(13 \%) \text {, multiple } \\
\text { sources } n=6(25 \%)\end{array}$ & $\begin{array}{l}\text { Medical sources } n=18(26 \%) \text {, } \\
\text { media } n=21(31 \%) \text {, other } \\
\text { patients } n=8(12 \%) \text {, multiple } \\
\text { sources } n=20(30 \%)\end{array}$ & $\begin{array}{l}\text { Medical sources } n=17(37 \%) \text {, } \\
\text { media } n=12(27 \%) \text {, other } \\
\text { patients } n=3(7 \%) \text {, multiple } \\
\text { sources } n=14(30 \%)\end{array}$ \\
\hline $\begin{array}{l}\text { Aware of the phenomenon of dyskinesia } \\
\text { before the survey (or, in group III, before } \\
\text { developing dyskinesia) (\% of total) }\end{array}$ & $\begin{array}{l}\text { Yes } n=24(46 \%), \text { no } \\
n=28(54 \%)\end{array}$ & $\begin{array}{l}\text { Yes } n=68(67 \%), \text { no } \\
n=34(33 \%)\end{array}$ & $\begin{array}{l}\text { Yes } n=46(44 \%) \text {, no } \\
n=59(56 \%)\end{array}$ \\
\hline $\begin{array}{l}\text { Aware that dyskinesia is related to } \\
\text { treatment with levodopa and other } \\
\text { dopaminergic agents? (\% of total) }\end{array}$ & $\begin{array}{l}\text { Yes } n=20(38 \%) \text {, no } \\
n=32(62 \%)\end{array}$ & $\begin{array}{l}\text { Yes } n=38(37 \%) \text {, no } \\
n=64(63 \%)\end{array}$ & $\begin{array}{l}\text { Yes } n=33(31 \%), \text { no } \\
n=72(69 \%)\end{array}$ \\
\hline \multirow[t]{2}{*}{ Current dopaminergic medications (n) } & None & L-dopa 87, DA 43, COMT-I 1 & L-dopa 105, DA 74, COMT-I 19 \\
\hline & & MAOB-I 11, amantadine 7 & MAOB-I 10, amantadine 41 \\
\hline
\end{tabular}

Group I, PD patients not on dopaminergic medications; group II, PD patients on dopaminergic medications but with no dyskinesias; group III, PD patients on dopaminergic medications with dyskinesias. The higher the UPDRS score, the more severe the impairment. Question 32 addresses the duration of dyskinesia and question 33 addresses the severity of dyskinesia.

*Patient exclusions: five because of cognitive problems (UPDRS question $1>1$ ), one because of significant depression (UPDRS question $3>1$ ), two unable to distinguish between tremor and dyskinesia.

†Not significant.

$\neq \mathrm{p}<0.0001$ comparing groups I and III, and groups II and III.

$\S \mathrm{p}<0.0001$ comparing groups I and II, groups I and III, and groups II and III.

$\Phi p=0.0004$ comparing groups II and III.

${ }^{* *} \mathrm{p}=0.02$ comparing groups I and III; groups I versus II and II versus III were not significantly different.

DA: dopamine agonists; COMT-I: catechol-O-methyltransferase inhibitor; MAOB-I: monoamine oxidase B inhibitor; n/a, not applicable; UPDRS, Unified Parkinson's Disease Rating Scale. 

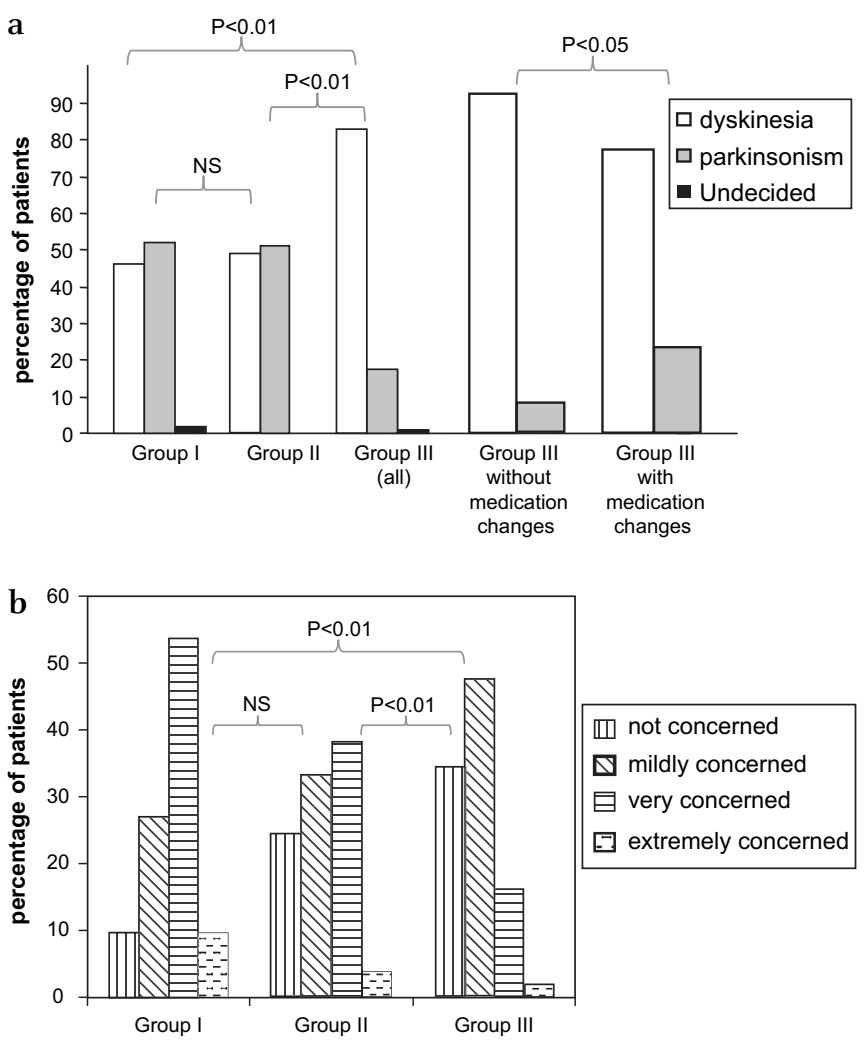

Figure 1 (A) PD patients without current dyskinesia (groups I and II) would prefer to tolerate parkinsonism than dyskinesia; PD patients with current dyskinesia preferred to have dyskinesia than parkinsonism. Within group III, there is a significant difference in preference between patients who have had medication changes because of dyskinesia and those who did not. Figure showing patient preference of dyskinesia or parkinsonism in the three groups of patients. See legend for table 1. The distribution is significantly different between groups I and III, and between groups II and III $(p<0.01)$. There is no significant difference between groups I and II. Among group III patients, those who did not have to change medication because of dyskinesia are more likely to prefer dyskinesia to parkinsonism $(p<0.05)$. (B) PD patients without dyskinesia (groups I and II) were more concerned about dyskinesia than PD patients with dyskinesia (group III). In B, the level of concern about dyskinesia was shown among the three groups of patients rated using the scale as described in the text (see legend for table 1). The distribution is significantly different between groups I and III, and between groups II and III $(p<0.01)$. There is no significant difference between groups I and II (NS). PD, Parkinson's disease.

with PD who have experienced dyskinesia, when given a choice between being parkinsonian or having less parkinsonian symptoms, but at the expense of having dyskinesia, choose the latter. In the groups of patients without dyskinesia (groups I and II), the choice was more evenly distributed between dyskinesia and parkinsonism. Not surprisingly, the level of concern regarding dyskinesia also tended towards "not concerned" and "mildly concerned" in the group of patients with first-hand experience with dyskinesia compared to patients without dyskinesia. The effect of dyskinesia on quality of life has been controversial. ${ }^{12} 13$ In a recent study from the Mayo Clinic, although dyskinesia was increasingly common over $\geq 5$ years of L-dopa treatment, cases of dyskinesia severe enough to require medication adjustments and especially cases of dyskinesia resistant to medication adjustments were uncommon. ${ }^{14}$ The results of the current survey, that patients with more advanced disease, despite having greater problems with quality of life, would choose dyskinesia over parkinsonism suggest that, for most patients, dyskinesia may play a less important role in the determination of quality of life compared to other factors such as progression of disease and motor fluctuations.

The predominant current treatment strategy of delaying L-dopa treatment by using dopamine agonists instead, at the possible cost of reduced efficacy and an arguably worse side effect profile, ${ }^{9}$ is based largely on the assumption that dyskinesia is undesirable and likely disabling. However, there is little evidence that the delay in dyskinesia with initial agonist treatment translates into a long-term advantage of improved quality of life. ${ }^{1516}$ The current survey does not diminish the urgency of developing more effective and safer therapies; however, until better solutions are available, our results emphasise that a concern about the future development of dyskinesia, which often drives a form of "L-dopa phobia", ${ }^{17}$ should not compromise optimal control of parkinsonism.

There are limitations to our study. Ideally, a longitudinal study would be more accurate in exploring changes in patient perception of disease progression, but it would be difficult and expensive. For practical purposes, UPDRS motor scores were obtained at routine clinic visits rather than in defined off states, which would have better reflected the severity of the disease in the treated patients. Although there may have been poorly understood cultural, educational, economical and social factors that could have influenced the results of the survey, patients were recruited prospectively mainly from one large metropolitan movement disorders clinic in Canada that services a multicultural population in a socialised healthcare system. Overall, patients in group III had mild to moderate dyskinesia. However, we did not preselect or exclude patients with more severe forms of dyskinesia who might have been more concerned about this side effect. Our sample is representative of patients attending a subspecialty movement disorders clinic, which probably represents a population with more severe motor complications than a community-based sample.

We have shown that patients with first-hand experience of dyskinesia are less likely to be concerned about the side effect and are more likely to prefer dyskinesia over increased symptoms of parkinsonism. Because quality of life may be more dependent on the severity of parkinsonism and less on the presence of dyskinesia, this observation should be taken into account by prescribers and patients in making an informed decision regarding initial treatment strategies in $\mathrm{PD}$.

Funding SWH has received financial support for research and speaker fees from St. Jude Medical Neuromodulation Division, UCB Pharma and Teva Neuroscience. GMA has nothing to disclose; TA has nothing to disclose; SHF has received financial support for research, consultancy and speaker fees from Novartis, Kyowa, Teva, Eisai, GW Bayer, Prestwick, GlaxoSmithKline; and AEL has received consulting fees or honoraria from Boerhinger-Ingelheim, Ceregene, Eisai, Medtronic, Novartis, Prestwick, Serono, Solvay, Taro and Teva.

\section{Competing interests None.}

Ethics approval This study was conducted with the approval of the institutional review boards of the University of Toronto and the Medical College of Wisconsin.

Contributors Study concept and design: AEL, SWH. Acquisition of data: SWH, GMA, SHF. Analysis and interpretation of data: TA, SWH, AEL. Drafting of the manuscript SWH, SHF, AEL. Critical revision of the manuscript for important intellectual content: SWH, SHF, AEL, GMA, TA. Statistical analysis: TA.

Provenance and peer review Not commissioned; externally peer reviewed.

\section{REFERENCES}

1. Rascol 0, Brooks DJ, Korczyn AD, et al. A five-year study of the incidence of dyskinesia in patients with early Parkinson's disease who were treated with ropinirole or levodopa. 056 Study Group. N Engl J Med 2000;342:1484-91. 
2. Rascol 0, Brooks DJ, Korczyn AD, et al. Development of dyskinesias in a 5-year trial of ropinirole and L-dopa. Mov Disord 2006;21:1844-50.

3. Frucht S, Rogers JD, Greene PE, et al. Falling asleep at the wheel: motor vehicle mishaps in persons taking pramipexole and ropinirole. Neurology 1999;52:1908-10.

4. Paus S, Brecht HM, Koster J, et al. Sleep attacks, daytime sleepiness, and dopamine agonists in Parkinson's disease. Mov Disord 2003:18:659-67.

5. Voon V, Hassan K, Zurowski M, et al. Prevalence of repetitive and reward-seeking behaviors in Parkinson disease. Neurology 2006;67:1254-7.

6. Voon V, Hassan K, Zurowski M, et al. Prospective prevalence of pathologic gambling and medication association in Parkinson disease. Neurology 2006;66:1750-2.

7. Nirenberg MJ, Waters C. Compulsive eating and weight gain related to dopamine agonist use. Mov Disord 2006;21:524-9.

8. Evans AH, Katzenschlager R, Paviour D, et al. Punding in Parkinson's disease: its relation to the dopamine dysregulation syndrome. Mov Disord 2004;19:397-405.

9. Parkinson Study Group. Long-term effect of initiating pramipexole vs levodopa in early Parkinson disease. Arch Neurol 2009;66:563-70.

10. Litvan I, Bhatia KP, Burn DJ, et al. Movement Disorders Society Scientific Issues Committee report: SIC Task Force appraisal of clinical diagnostic criteria for Parkinsonian disorders. Mov Disord 2003;18:467-86.
11. Shoulson I, Lang A, Fahn S, et al. Evaluation of dyskinesias in a pilot, randomized placebo-controlled trial of remacemide in advanced Parkinson disease. Arch Neurol 2001:58:1660-8.

12. Pechevis $\mathbf{M}$, Clarke CE, Vieregge $\mathbf{P}$, et al. Effects of dyskinesias in Parkinson's disease on quality of life and health-related costs: a prospective European study. Eur J Neurol 2005:12:956-63.

13. Marras C, Lang A, Krahn M, et al. Quality of life in early Parkinson's disease: impact of dyskinesias and motor fluctuations. Mov Disord 2004;19:22-8.

14. Van Gerpen JA, Kumar N, Bower JH, et al. Levodopa-associated dyskinesia risk among Parkinson disease patients in Olmsted County, Minnesota, 1976-1990. Arch Neurol 2006;63:205-9.

15. Katzenschlager R, Head J, Schrag A, et al. Fourteen-year final report of the randomized PDRG-UK trial comparing three initial treatments in PD. Neurology 2008; 71:474-80.

16. Hauser RA, Rascol 0, Korczyn AD, et al. Ten-year follow-up of Parkinson's disease patients randomized to initial therapy with ropinirole or levodopa. Mov Disord 2007 22:2409-17.

17. Kurlan R. "Levodopa phobia": a new iatrogenic cause of disability in Parkinson disease. Neurology 2005;64:923-4. 